\title{
In the Field
}

\section{Makerspaces in Libraries: On Challenges to Our Democratic Values}

There are children lined up to use the Nintendo gaming console, some as young as four or five years old. Parents are scrambling to gather their children who are transfixed by the glowing media on colossal flat screen televisions. The children are unresponsive, unruly, and unengaged from reality.

Libraries as enablers of commodified space is all too real in this Saturday afternoon example at the public libraries where I have worked. Library managers argue everyone should have access to new technologies. But what does this mean for the public sphere when the bookshelves and staff have been replaced by entertainment zones? Patrons- including those barely old enough to read- are cast into an altered environment encouraging highly addictive behaviour that rewards violence, hours played and ruthless competition. Makerspaces have the potential to be a model of learning-by-doing in which individuals can work on creative projects that are personally and collectively meaningful. The possibility to play, invent and design acts as a social glue for people to come together and engage in collaborative and creative endeavors (Gauntlett \& Thomsen, 2013). This vision, however, is hampered by the dangers of commodification through screen-based technology which is increasingly common in my work experience.

As a Library Technician for almost a decade, I've witnessed firsthand the demise of healthy media consumption in libraries and the digital monopolization of children's 
attention. As soon as iPads were made available for young learners, books became secondary. Going to the library quickly became a fight for more time on the iPad, and the entire atmosphere became glaringly void of human connection. The central purpose was no longer about sharing stories, songs and play-time together, nurturing early family relationships and inspiring curious literate citizens. Three and four-year-olds were hooked on shiny new objects. My role was relegated to tantrum referee, prying iPads or Nintendo consoles out of kindergarteners' frantic grip for an endless line of eager hyperenchanted users.

Social isolation through technology has become the norm. My colleagues have commented on their disapproval and sadness over the de-humanization of the next generation. Instead of emphasizing language literacy, family bonding and socialemotional skills, the hyper-inflated focus from a young age is technology with detrimental effects. Most concerningly, studies continue to show that children who rely on screen-based technology at a young age have lower literacy development leading to poorer educational outcomes (Hutton et. al., 2019). With longstanding democratic principles like increasing access to open and meaningful learning opportunities in our profession, I'm troubled by the proliferation of commodification by private interest in public libraries, especially when this is some of the only remaining public space left in our communities. Libraries are tax-payer funded resources where we can effectively model healthy media consumption for our young citizenry. Thus, it is where the potential for children's learning and innovation in makerspaces can reach phenomenal new heights. One such example is the remodelling of San Jose Public Library's children's space where hands-on, tactile play-based development is central to the maker ethos 
they impart. Nature activities, musical instruments, puzzles and simple STEAM kits are built into the architecture (SJPL, 2021). Why isn't this vision upheld as universal in makerspace funding decisions in our field?

Libraries are the perfect place for manufacturers and big corporations to model their new technologies and gain access to wider markets. Libraries can boast of new high-tech innovation in an increasingly business-oriented service model. In addition, I have seen how libraries have been facing an identity crisis ever since Google emerged.

The fight to maintain relevance in the $21^{\text {st }}$ century with lessening traditional reference statistics has forced libraries to reinvent their image as worthy for the public good. Third spaces, ones besides a person's home or workplace focused on learning in new ways have allowed libraries to survive as open places of discovery. But the promotion of privatized capital and not the public good deviates from the founding democratic mandate of the library and should be of grave concern to LIS professionals. Samuel Trosow (2015) questions the core problems with emphasizing "entertainment centric" makerspaces to gain funding and draw more "customers" by referencing his peer, John Buschman:

As a society, do we really need another model of market and market-driven consumer space, or do we need another alternative in the public sphere"?... I would reframe the question and ask: Is librarianship itself succumbing to the commodification of information and to the erosion of the public sphere, all to the detriment of what we had thought were our basic values of intellectual freedom, broad access to information and public control over the policies that determine information policies? (p. 24). 
These questions should be central to any strategic and financial planning that decides the future of public library services, including makerspaces.

I have had to accept the fact that many women and girls do not feel welcome in makerspaces that are geared toward traditionally male-dominated disciplines of computer science, engineering, sciences, and audio/visual production. While libraries provide these spaces for public engagement, encouraging female participation and not reaffirming the gendered status quo requires self-awareness and planning on the part of libraries. Betser et al. (2019) studied young women attending a maker program where female empowerment was a major goal. Their findings concluded that many young women felt limited in traditional STEM settings, including makerspaces, and attending a program that was all girls and outside of their home community opened new horizons where they could feel welcomed, safe, and supported in their unchartered learning. Young women reported feeling exuberant in their exploring the question "What kind of girl am I?" as the program helped young women interested in STEM develop positive associations with this identity (Betser et al., 2019). In Bean's study (2015), it is stated that $81 \%$ of U.S. makers are men and women often are undercounted because the type of making they take part in comes from a nontechnical path. Bean's survey indicated that women are more likely to come from an arts-and-crafts background, whereas men are more likely to engage with engineering or physical sciences. It seems that a common misconception about the Maker Movement is that knitting, sewing, painting, sculpting, and so on do not fit in with technology and engineering. However, the Maker Movement is not solely about science and engineering - it is also about enabling a community of creators to collaborate in order to create in new ways. This includes new 
and creative approaches, such as combining 3-D printing technology with textiles and adding light-up computer chips to sculpture. By recognizing this gender gap and adhering to empowering practices that celebrate the diverse skills and potential women bring, libraries can provide more welcoming and equitable makerspaces.

To illustrate, when I started a program titled "Textile Art for Kids" in 2019 at an urban library branch on Vancouver Island, the reception was popular among girls and young women aged 8-13. Suddenly they felt like a part of the makerspace and started using the space outside of the program regularly. By celebrating 'low-tech' crafting as a viable, fun STEAM activity, it appealed to an under-represented demographic that wasn't being reached previously. This in turn inspired positive and creative learning outcomes that was a catalyst for girls to feel welcomed in the space, develop new skills for creation, and increase overall makerspace participation and diversity.

However, for anyone to feel well served in library makerspaces, proficient, satisfied staff are essential. Koh and Abbas (2015) identify a lack of research studies into the skills and competencies required to run makerspaces within libraries or museums, nor any official list of competencies by professional LIS bodies. As a staff member fielding multiple requests for assistance at once, it is overwhelming to selfteach a myriad of DIY skills as part of new job duties and manage patron expectations with little support. Koh and Abbas (2015) list management, diverse program development, and adaptive facilitation as necessary skills for makerspace staff members. I have found all three of these skill sets to be lacking and thus, it is a mischaracterization that traditional librarian conduct translates equally to a makerspace environment. A negative user experience often results when staff fail to successfully 
engage visitors, provide proficient guidance and manage expectations. While selfdirected reading and request-based reference services work in a traditional library setting, makerspaces require more in-depth interpersonal and management skills that tailor to specific user needs and abilities. In contrast to a book, it is unlikely most patrons have operated a 'Green Screen' before. It is up to staff to break down those barriers and build accessible and welcoming spaces.

In addition, integrating technical competencies into everyday library practice requires regular training and job descriptions that reflect these changes. Most importantly, I believe compensation for the added value specialized staff bring to library makerspaces would incentivize professional growth and strengthen ties to the organization.

Navigating the changing information landscape of the $21^{\text {st }}$ century is no easy task as libraries continue to face challenges such as the underrepresentation of women and girls in makerspaces and the commodification of library spaces through entertainment zones and its profound effects on early childhood development. As such, it is imperative that librarians carry on the democratic traditions of our field by ensuring the public sphere prevails through modelling healthy media consumption and diverse literacy mandates as we re-make $21^{\text {st }}$ century libraries. To do so, adequately compensating and reinventing professional development to train new and established librarians is required. As my field experience highlights, our public libraries are in critical need of adaptive facilitators for welcoming and democratic spaces that impart unbranded, tactile, collaborative and creative skills-based 'learning-by-doing.'

\section{Dalia Levy}


Levy, D. (2021). Makerspaces in libraries: On challenges to our democratic values. Emerging Library \& Information Perspectives, 4, 206-213. https://doi.org/10.5206/elip.v4i1.13479

\section{References}

Betser, S., Lee, M. M., \& Ambrose, R. (2019). “They Don't See Girls”: Construction of Identities in a Maker Program. Atlanta: American Society for Engineering Education-ASEE.

Bean, F. (2015). An exploration of women's engagement in Makerspaces. Gifted and Talented International, 30(1-2), 61-67 https://doi.org/10.1080/15332276.2015.1137456

Gauntlett, D., \& Thomsen, S. B. (2013). Cultures of Creativity. https://www.legofoundation.com/media/1073/cultures-of-creativity-lego-fonden2013.pdf

Hutton, J., Dudley, J., Horowitz-Kraus, T., DeWitt, T., Holland, S. (2019). Associations Between Screen-Based Media Use and Brain White Matter Integrity in Preschool-Aged Children. JAMA Pediatrics, 2019; e193869 https://doi.org/10.1001/jamapediatrics.2019.3869h

Koh, K., \& Abbas, J. (2015). Competencies for information professionals in learning labs and Makerspaces. Journal of Education for Library and Information Science, 56(2), 114-129. http://dx.doi.org/10.12783/issn.2328-2967/56/2/3

San Jose Public Library. (2021). Wee Programs. https://www.sjpl.org/wee-programs 
Trosow, S. (2015). The Commodification of Information and the Public Good: New Challenges for a Progressive Librarianship. Progressive Librarian, (43), 17-29. 